\title{
Influence of Pre-Aging on the Hardness and Formability of a Thread Rolled 6056 Aluminum Alloy after Conventional Extrusion and Artificial Aging
}

\author{
Lisa Winter ${ }^{1, *(D)}$, Ralph Jörg Hellmig ${ }^{2,3}$, Kristin Hockauf ${ }^{1,4}$ and Thomas Lampke ${ }^{1(D)}$ \\ 1 Institute of Materials Science and Engineering, Chemnitz University of Technology, \\ D-09125 Chemnitz, Germany; hockauf@hs-mittweida.de (K.H.); thomas.lampke@mb.tu-chemnitz.de (T.L.) \\ 2 EJOT GmbH and Co. KG., Industrial Fasteners Division, D-57319 Bad Berleburg, Germany; \\ rhellmig@ejot.com \\ 3 Institute of Materials Engineering, University of Siegen, D-57068 Siegen, Germany \\ 4 Chair of Smart Materials, Department of Engineering Sciences, Mittweida University of Applied Sciences, \\ D-09648 Mittweida, Germany \\ * Correspondence: lisa.winter@mb.tu-chemnitz.de
}

Citation: Winter, L.; Hellmig, R.J.; Hockauf, K.; Lampke, T. Influence of Pre-Aging on the Hardness and Formability of a Thread Rolled 6056 Aluminum Alloy after Conventional Extrusion and Artificial Aging. $J$. Manuf. Mater. Process. 2021, 5, 116 https://doi.org/10.3390/jmmp5040116

Academic Editor: Steven Y. Liang

Received: 8 October 2021

Accepted: 27 October 2021

Published: 29 October 202

Publisher's Note: MDPI stays neutral with regard to jurisdictional claims in published maps and institutional affiliations.

Copyright: (c) 2021 by the authors. Licensee MDPI, Basel, Switzerland. This article is an open access article distributed under the terms and conditions of the Creative Commons Attribution (CC BY) license (https:// creativecommons.org/licenses/by/ $4.0 /)$.
Abstract: For the production of aluminum screws, an effective thermomechanical treatment is necessary for enabling high strength combined with good formability. In this study, the influence of pre-aging as initial heat treatment prior to following processing steps was investigated for the precipitation hardenable 6056 aluminum alloy. The short-term low temperature pre-aged condition was compared to a naturally aged one representing storage time in manufacturing. As reference, a solution-annealed condition was used. After these initial heat treatments, conventional extrusion and artificial aging followed prior to final thread rolling. The distribution of strain introduced by these forming processes was numerically investigated using finite element simulation. The initial heat treatment had a significant influence on the mechanical properties achievable after the complete thermomechanical processing route. After extrusion and artificial aging, the highest hardness was achieved by the pre-aged condition. Despite its high initial hardness, this condition exhibited the best formability indicated by well-formed threads combined with the highest hardness achieved after thread rolling. Therefore, pre-aging seems to be an advantageous heat treatment for integration in the manufacturing process of screws due to its beneficial effect on the mechanical properties.

Keywords: aluminum alloy; thermomechanical treatment; pre-aging; natural aging; linear extrusion; thread rolling; hardness

\section{Introduction}

Aluminum screws are a favored option for joining lightweight metal components in the automotive and aerospace sector. When compared to conventional steel screws, the application of aluminum provides significant advantages [1]. A low total weight of the structural component can be maintained due to the low density of the aluminum alloy. Further, as similar materials for the components being joined and the screws are paired, galvanic corrosion is minimized [2]. The loss in clamping forces is reduced due to the minimized difference of the thermal expansion coefficients of the clamped parts and therefore, high clamping forces are maintained even under long-term thermal loading [1,3,4] Furthermore, the minimum installation depth can be reduced [1].

By using high-strength aluminum alloys of the 7xxx series, e.g., Al7075 or 7068, a yield strength in the range of a conventional screw made of steel is achievable [1,4,5]. However, when compared to steel, those aluminum alloys are significantly more expensive and their high strength is accompanied by a loss in formability. Furthermore, aluminum alloys of the 7xxx series exhibit a higher susceptibility to stress corrosion cracking [6] when compared to the lower-cost alloys of the 6xxx series, which exhibit lower strength. 
Therefore, it is necessary to develop an effective processing regime that enables high strength and good formability for alloys of the 6xxx series for the cost and resource efficient production of aluminum screws. One of the most used aluminum alloys for screws is Al6056 (AlSi1MgCuMn) due to the good formability and the high strength achievable by precipitation hardening. The order of the thermal and mechanical treatment directly influences the mechanical properties achieved and therefore, the further formability. Using thermal treatment solely, the highest hardness and strength can be realized by artificial aging. However, in the case of prior natural aging of the 6056 alloy, the resulting precipitates lead to significant loss in the hardening response during further artificial aging $[7,8]$. As interim storage periods at room temperature are often unavoidable in the industrial screw manufacturing process, e.g., due to transportation to different production locations or washing between single processing steps, preventing naturally aging can be important. An effective and common strategy to achieve an increased room temperature stability of precipitation hardenable aluminum alloys is a pre-aging treatment. After solution-annealing, the alloys are short term pre-aged at temperatures considerably lower than artificial aging temperatures, which inhibits natural aging for a certain amount of time [8-11]. Furthermore, pre-aging has a positive effect on the hardness and strength achievable in the following processing $[9,10]$.

In our own previous study [12], the influence of the initial heat treatment on the artificial aging response after conventional linear extrusion was investigated with focus on the precipitation kinetics. The beneficial influence of pre-aging of a 6056 aluminum alloy was shown as natural aging was inhibited for two weeks and furthermore, the hardness achieved after extrusion and artificial aging was significantly higher, when compared to a condition, which was naturally aged prior to further processing. In the industrial manufacturing process of aluminum screws, thread rolling is commonly the last processing step. As formability by thread rolling is directly influenced by strength and hardness of the material, this study was designed to answer the following questions: (1) "Does the higher hardness achieved by pre-aging impede the forming of threads?" and (2) "Is the maximum hardness achieved after thread rolling and the previous processing steps influenced by the initial heat treatment of the aluminum alloy?".

\section{Materials and Methods}

\subsection{Material and Processing Route}

A commercial 6056 (AlSi1MgCuMn) aluminum wire with a diameter of $5.25 \mathrm{~mm}$ was investigated in this study. The material was provided by EJOT GmbH \& Co. KG (Bad Berleburg, Germany) and is used in the industrial process for manufacturing screws. This high-strength alloy is precipitation hardenable by natural as well as artificial aging and exhibits a good formability, in general. Chemical composition and mechanical properties of the initial wire as received are listed in Table 1.

Table 1. Chemical composition and initial properties of the used commercial 6056 (AlSi1MgCuMn) aluminum wire as received.

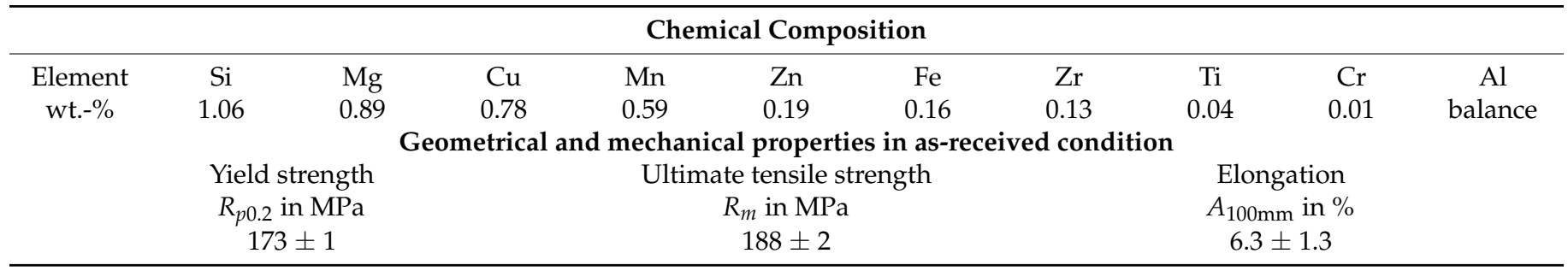

Three different processing routes were compared to systematically investigate the initial heat treatment as factor influencing the hardness achieved and the remaining formability (see Table 2). A condition, which was naturally aged for 7 days at room temperature and which represents material stored temporarily in the industrial manufacturing process, 
was compared to a pre-aged condition, which was annealed for $5 \mathrm{~h}$ at $80{ }^{\circ} \mathrm{C}$. Prior to the respective heat treatment, both conditions were solution annealed for $1 \mathrm{~h}$ at $530{ }^{\circ} \mathrm{C}$ followed by quenching in water to room temperature. As a reference, a solution-annealed condition using these parameters was investigated as well.

Table 2. Investigated processing routes of the used commercial 6056 aluminum wire.

\begin{tabular}{|c|c|c|c|}
\hline \multirow{2}{*}{ Processing Step } & \multicolumn{3}{|c|}{ Processing Route } \\
\hline & A & B & $\mathrm{C}$ \\
\hline 1 & $\begin{array}{l}\text { solution-annealing } \\
\text { for } 1 \mathrm{~h} \text { at } 530{ }^{\circ} \mathrm{C}, \\
\text { water-quenching to } \\
\text { room temperature }\end{array}$ & $\begin{array}{c}\text { solution-annealing for } 1 \mathrm{~h} \text { at } 530^{\circ} \mathrm{C} \text {, } \\
\text { water-quenching to room } \\
\text { temperature and naturally aged } \\
\text { for } 7 \mathrm{~d} \text { at room temperature }\end{array}$ & $\begin{array}{l}\text { solution-annealing for } 1 \mathrm{~h} \\
\text { at } 530^{\circ} \mathrm{C} \text {, water-quenching to } \\
\text { room temperature and } \\
\text { pre-aged for } 5 \mathrm{~h} \text { at } 80^{\circ} \mathrm{C}\end{array}$ \\
\hline 2 & & linear extrusion with $\varphi=1.2$ & \\
\hline 3 & & artificial aging at $120^{\circ} \mathrm{C}$ up to $6 \mathrm{~h}$ & \\
\hline 4 & & thread-rolling & \\
\hline
\end{tabular}

For this study, a linear extrusion process was used for plastic deformation in a laboratory scale. EJOT GmbH \& Co. KG (Bad Berleburg, Germany) extruded the heat-treated wire studs at room temperature. For comparability to the manufacturing process of screws, a strain introduced of $\varphi=1.2$ was chosen. The strain introduced was measured by the reduction of the initial wire cross-section $A_{0}$ to the wire cross-section after extrusion $A_{1}$ :

$$
\varphi=\ln \frac{A_{0}}{A_{1}}
$$

Following linear extrusion, the wire studs were artificially aged up to $6 \mathrm{~h}$ at $120^{\circ} \mathrm{C}$ for precipitation hardening. The influence of the three initial heat treatment conditions compared followed by extrusion and artificial aging on the precipitation sequence and the hardness achieved is described in detail in the own previous study [12].

For the investigation of the remaining formability dependent on the initial heat treatment and the hardness achieved by artificial aging, the extruded and artificial aged wire studs were thread rolled by EJOT GmbH \& Co. KG (Bad Berleburg, Germany). The geometry of the thread rolling dies was adjusted to the diameter of the wire studs. For each initial heat treatment condition, two artificial aging times, resulting in a first and second hardness peak, respectively, for the aging time investigated, were chosen for following thread rolling.

\subsection{Mechanical and Microstructural Characterization}

Regarding the mechanical properties, the three processing routes are mainly compared by the hardness achieved, as measuring the hardness is a fast and effective method due to the correlation to the static strength. Vickers hardness in HV0.1 was measured with 20 indentations from edge to core on the metallographically polished wire cross-sections for each condition using a Durascan 70 G5 automatic hardness tester (EMCO-TEST Prüfmaschinen $\mathrm{GmbH}$, Kuchl, Austria) and plots of hardness as a function of the artificial aging time were generated. Further, the hardness achieved after thread rolling was determined on the metallographically polished longitudinal section of the threaded parts with 5 indentations on the thread root and 5 indentations on each thread flank of one tooth using a microhardness tester Tukon 1102 (Buehler, ITW Test \& Measurement GmbH, Esslingen am Neckar, Germany). Additionally, the distribution of the Martens hardness over the longitudinal area was determined by scanning a full section containing tooth and thread root of the polished specimens using an instrumented hardness tester Fischersope HM2000 XYm (Helmut Fischer GmbH, Sindelfingen, Germany) with $500 \mathrm{mN}$ loading force and $0.09 \mathrm{~mm}$ distance between the indents. 
After thread rolling, the threaded parts were optically analyzed using a stereo microscope (Carl Zeiss Microscopy Deutschland GmbH, Oberkochen, Germany). The focus of these investigations was on the overall appearance of the surface of the rolled threads and the teeth formed.

\subsection{FE-Simulation}

Accompanying the characterization of the material, finite element simulation of the linear extrusion and the thread rolling processes were performed using the software Simufact (Simufact Engineering GmbH, Hamburg, Germany). The aim was to predict the strain introduced in the aluminum wire over the cross section by the different forming steps. The thermal treatment and the resulting hardness was not a part of the simulation, as this complex interrelation could not be represented numerically by the used method.

The material chart used of the aluminum alloy 6056 was deposited in the software. The simulation has been carried out in two steps. The first step contained an axisymmetric simulation of the extrusion process (70\% reduction of cross section) to obtain input parameters for the rolling simulation. The procedure of a FE rolling simulation using flat rolling dies is described in [13]. The dies have been determined as rigid bodies while the wire stud has been defined as work piece. The initial mesh size was about $0.08 \mathrm{~mm}$; a proper remeshing procedure was defined to take care of locally high deformations. A Coulomb friction model was used for the rolling simulation assuming an average friction coefficient of $\mu=0.4$. A commercial material model for the alloy 6056 was used. This model was based on flow curve data obtained at various temperatures from $20^{\circ} \mathrm{C}$ to $240^{\circ} \mathrm{C}$ at different strain rates between 0.1 per second and 500 per second. To save calculation time, the rolling simulation was stopped as soon as the final thread geometry was reached. In a practical rolling process, a final calibration of the threaded part is carried out. Dies for extrusion and thread rolling were modeled based on their CAD design created in SolidWorks (Dassault Systèmes, Vélizy-Villacoublay, France).

\section{Results}

\subsection{Process Simulation of Conventional Extrusion and Thread Rolling}

The simulation results of the extrusion process are shown in Figure 1a. As expected, the strain introduced by extrusion is highest close to the outer surface and reaches values of about 2 in the case of 70\% area reduction. The wire core area exhibits a typical strain of about 1.2 after the same process. Therefore, the strain distribution becomes homogeneous along the wire axis, while there is a strain reduction of about $40 \%$ from the rim to the core of the wire.

This result is used as input data for the thread rolling simulations, as shown in Figure $1 \mathrm{~b}$. As the overall surface is still untouched (indicated by an effective plastic strain of about 2), material is removed from the core area inducing an increased local strain. These areas of high strain in this initial phase will become the area of thread roots when the thread is fully formed. In contrast, the area of low deformation will be moved to become part of the thread flanks.

Nevertheless, very high strains are introduced during thread rolling; see Figure 2. During thread rolling, the material forming the threads is moved from the wire surface into its new positive, followed by a calibration due to the die surface. A higher hydrostatic pressure is observed in the root area, from where the material is removed during processing. Therefore, after the rolling process, this area shows the highest strain, with approximately between 13 and 14. Even if the thread flank area exhibits a lower strain, values between 6 (thread tip) and 9 (central thread area) are achieved, which are still quite high. This demonstrates that thread rolling will have a strong effect on the resulting microstructures in both areas-flank and root. 

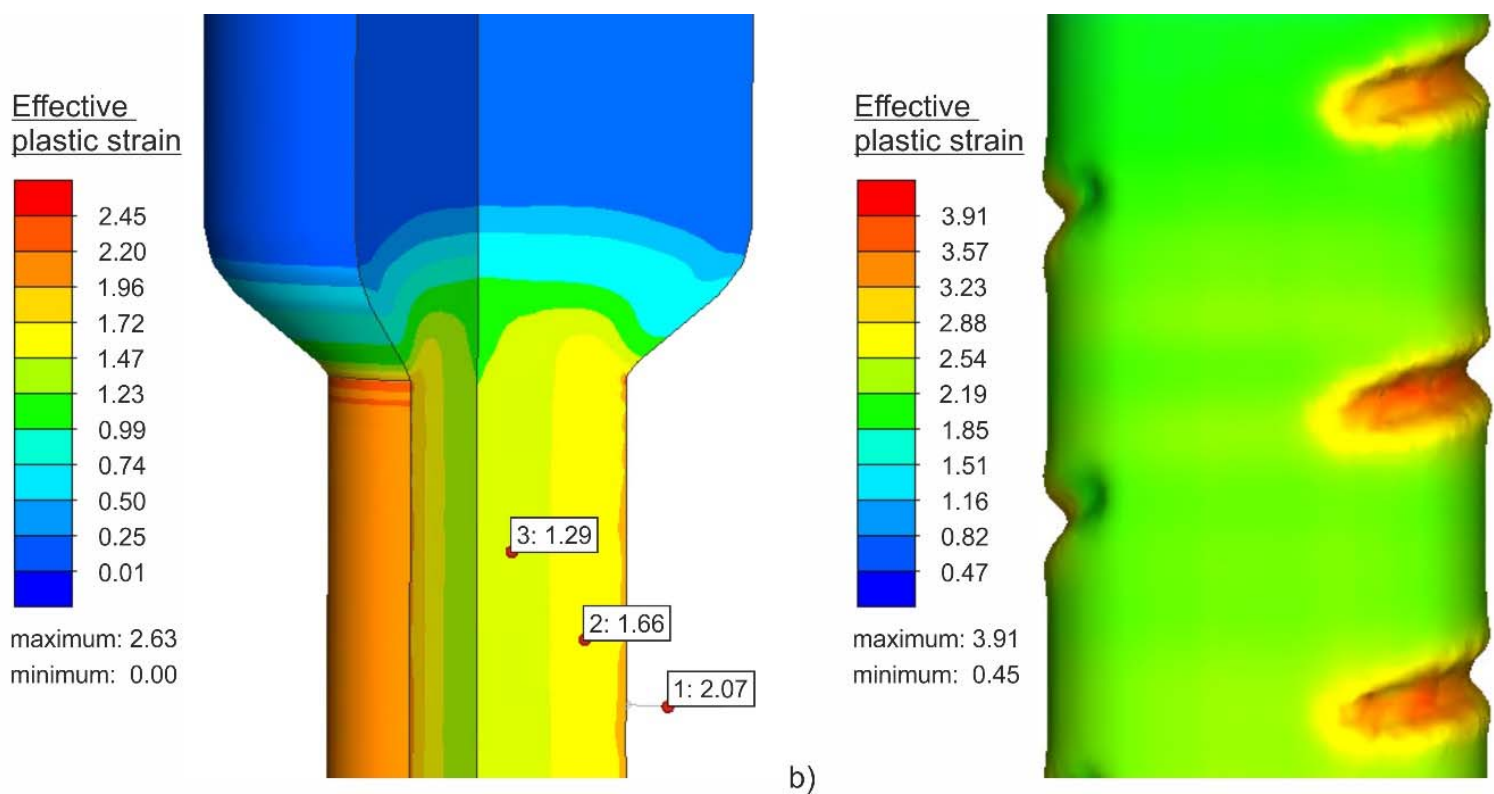

Figure 1. Finite element simulation of the (a) strain distribution after extrusion ( $70 \%$ area reduction) and (b) using these results for early stage thread rolling process. The strain introduced by extrusion is highest close to the outer surface and decreases with increasing distance to the surface.
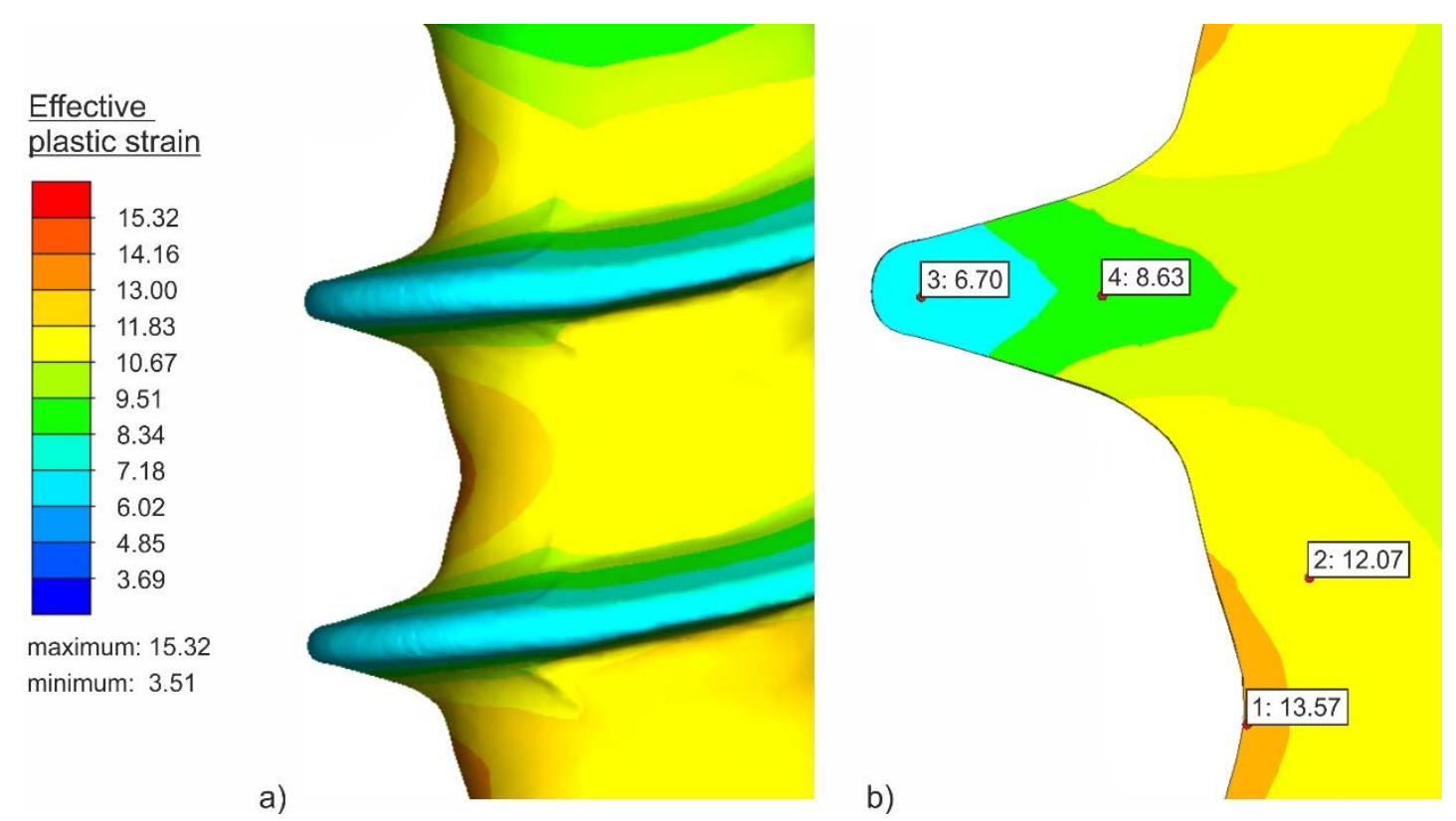

Figure 2. Finite element simulation of the strain distribution after thread rolling: (a) $3 \mathrm{~d}$ view and (b) cut through area. The area at the thread root shows the highest introduced strain, whereas the strain introduced is lowest at the thread tip.

\subsection{Hardness Prior to and after Thread Rolling}

The hardness achieved as a function of the artificial aging time after the three processing routes is shown in Figure 3. Within the investigated aging time, all three processing conditions exhibit a first and a second hardness peak. For the processing routes B and C, the profile of the hardness is quite similar, although the naturally aged condition (route $\mathrm{A}$ ) exhibits a significantly lower hardness. The highest hardness is achieved with route $C$ by pre-aging prior to extrusion. When compared to the other two processing routes, for route $\mathrm{C}$, the hardness is enhanced by $8 \%$. Although the level of hardness achieved is almost the same for the routes $\mathrm{A}$ and $\mathrm{B}$, for route $\mathrm{A}$, distinct differences are noticeable. The 
solution-annealed condition reaches the first and second hardness peak after the shortest artificial aging time but the hardness remains mostly below the naturally aged and entirely below the pre-aged condition.

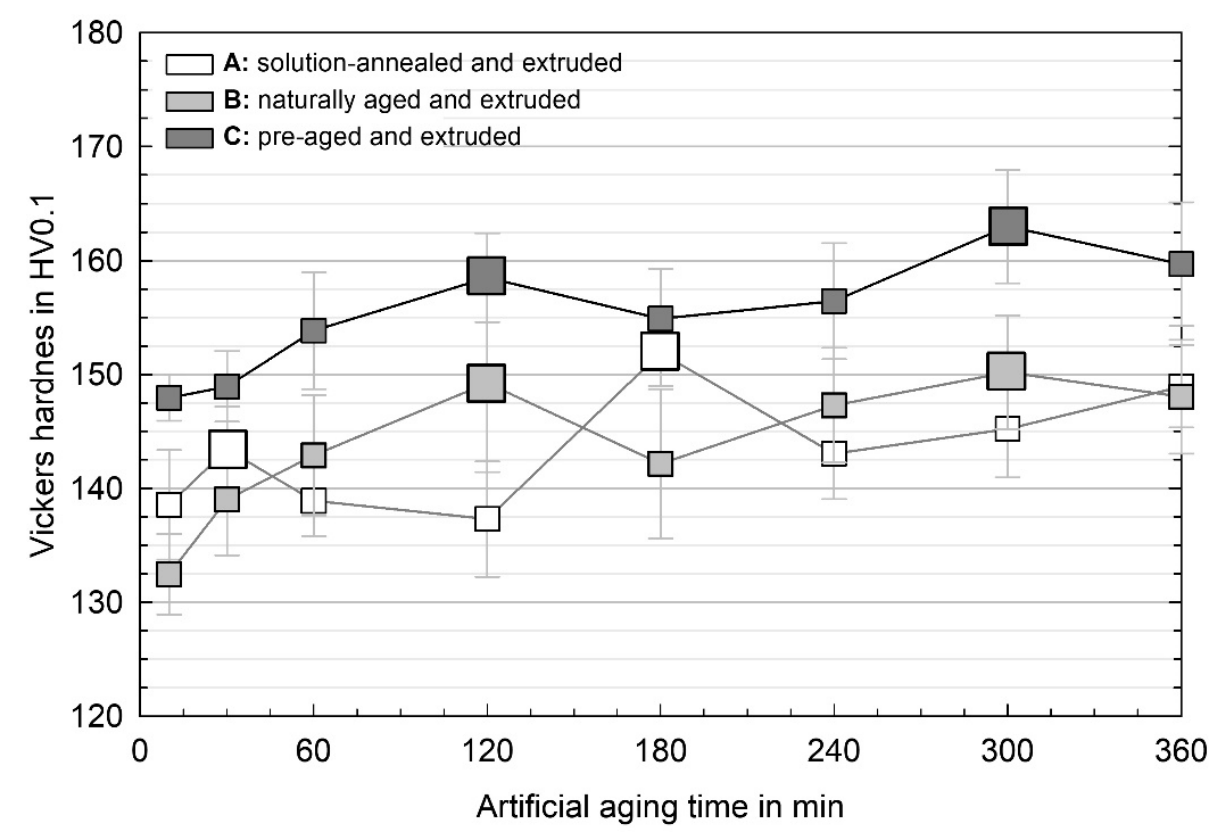

Figure 3. Vickers hardness as a function of the artificial aging time dependent on the processing route. The first and second hardness peak for the investigated maximum aging time is marked for each condition by a larger symbol. By pre-aging prior to linear extrusion, the highest hardness is achieved, when compared to the other processing routes.

In Figure 4, the hardness across half of the wire section, displayed as a function of the distance from the wire surface, is shown for the three different processing routes and the two artificial aging times chosen for each route. In general, independent of the processing route and the artificial aging time, with an increased distance from the surface, the hardness decreases. For a distance from the wire surface of $1.2 \mathrm{~mm}$, the hardness is decreased by approximately $8 \%$. Longer aging times lead to an increased hardness. The difference between the hardness achieved for both artificial aging times is most pronounced for processing route $\mathrm{A}$. The increase in artificial aging time from 30 to 180 min leads to an overall increase in hardness of $6 \%$, which shows in an almost parallel shift of the hardness curve to higher values (see Figure $4 a$ ). For processing route $C$ (initially pre-aged), the hardness increase due to a longer aging is lower (approximately 3\%) and the parallel shift of the hardness curve is not quite as strongly pronounced, when compared to processing route A. For the initially naturally aged condition (processing route B), the increase in hardness due to an increased artificially aging time is minor and the hardness curves for both aging times overlap. However, there is a pronounced difference for the core hardness when comparing both aging times, which is only observed for the naturally aged condition. 


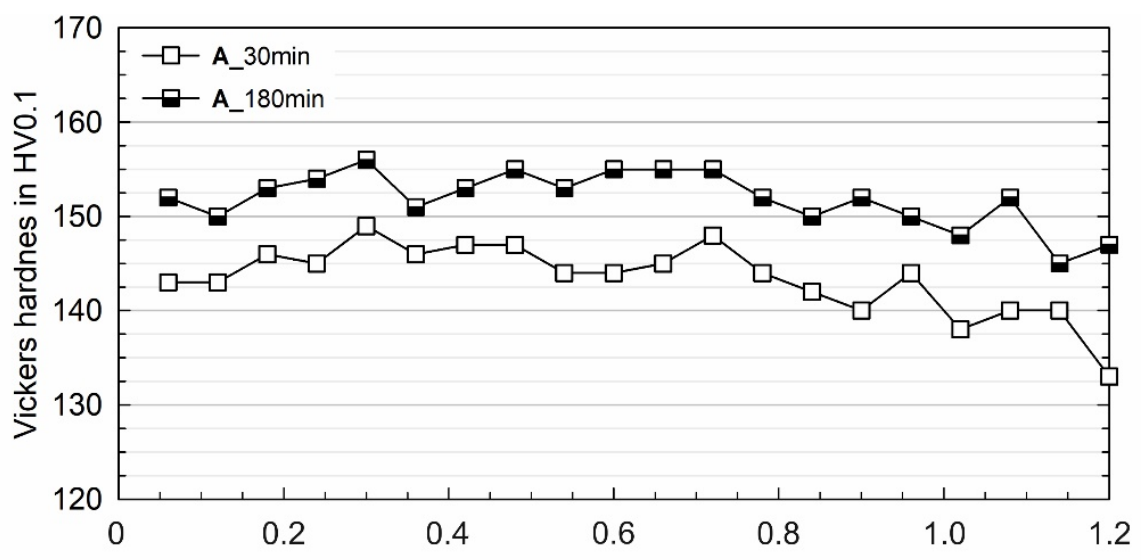

a)

Distance from surface in $\mathrm{mm}$

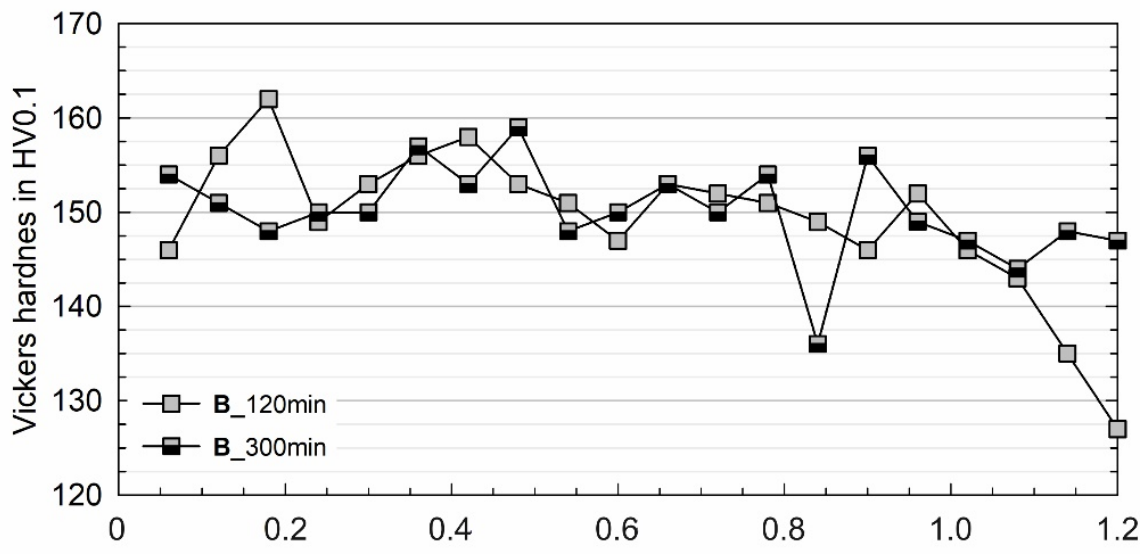

b)

Distance from surface in $\mathrm{mm}$

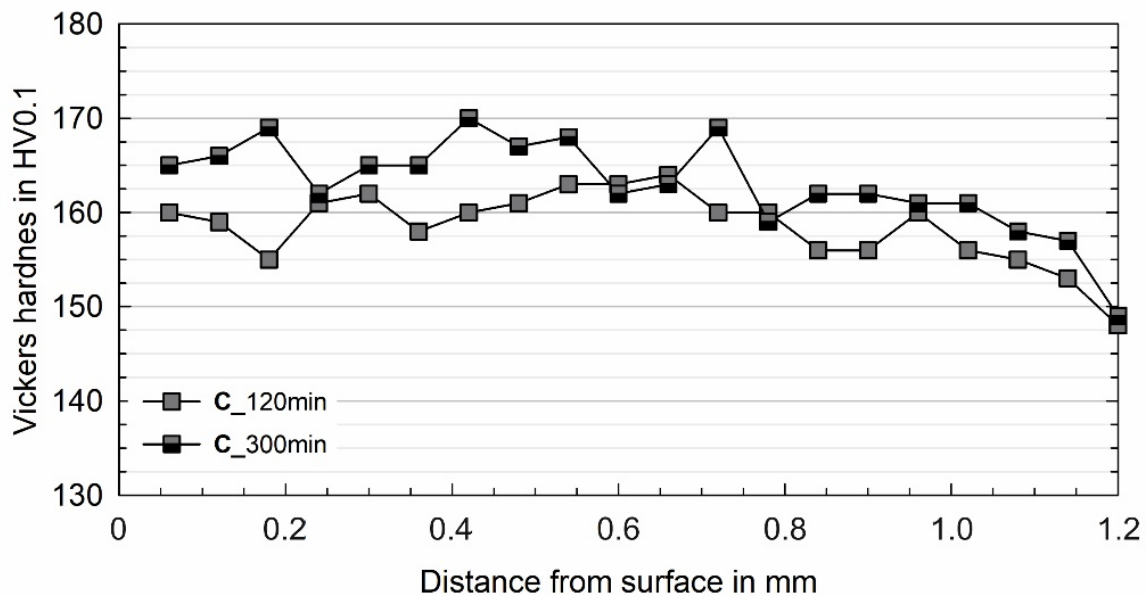

Figure 4. Vickers Hardness across half of the wire section measured for the three different processing routes dependent on the artificial aging time prior to thread rolling as a function of the surface distance: initial heat treatment condition (a) solution-annealed, (b) naturally aged and (c) pre-aged. For all processing routes and artificial aging times, the hardness decreases with the increasing distance from the surface.

For each of the three processing routes, the two artificial aging times resulting in a first and second hardness peak, respectively, were chosen for the further thread rolling process. Table 3 gives an overview of the hardness achieved prior to and after thread rolling for the chosen processing conditions. These results are further graphically presented in Figure 5. In general, the hardness is significantly enhanced after thread rolling, especially at the thread root. However, distinct differences between the hardness achieved for the 
three compared processing routes are noticeable. The highest hardness after thread rolling is achieved by processing route $\mathrm{C}$; although the percentage increase in hardness with $13-16 \%$ is slightly lower when compared to processing route A with $13-20 \%$. Prior to thread rolling, processing via route $B$ results in a hardness similar to that one of route $A$. However, the average percentage increase in hardness after thread rolling for processing via route $\mathrm{B}$ is with $8 \%$ minor, when compared to the other processing routes. In general, within the experimental range of this study, the artificial aging time prior to thread rolling seems not to be an influencing factor for the hardness achieved after thread rolling. The hardness is dependent on the processing route and therefore, in particular, on the initial heat treatment condition.

Table 3. Vickers hardness of different stages along the investigated processing routes of the aluminum wire alloy 6056.

\begin{tabular}{|c|c|c|c|c|}
\hline \multirow{3}{*}{ Processing Route } & \multirow{3}{*}{$\begin{array}{l}\text { Artificial Aging } \\
\text { Time in Min }\end{array}$} & \multicolumn{3}{|c|}{ Hardness in HV0.1 } \\
\hline & & \multirow{2}{*}{$\begin{array}{c}\text { Prior to } \\
\text { Thread Rolling }\end{array}$} & \multicolumn{2}{|c|}{ after Thread Rolling } \\
\hline & & & Thread Root & Thread Flank \\
\hline A & 30 & $143 \pm 4$ & $171 \pm 2$ & $168 \pm 4$ \\
\hline (solution-annealed, extruded) & 180 & $152 \pm 3$ & $172 \pm 4$ & $172 \pm 3$ \\
\hline B & 120 & $149 \pm 8$ & $160 \pm 7$ & $159 \pm 4$ \\
\hline (naturally aged, extruded) & 300 & $150 \pm 5$ & $164 \pm 4$ & $163 \pm 3$ \\
\hline C & 120 & $159 \pm 4$ & $185 \pm 4$ & $178 \pm 3$ \\
\hline (pre-aged, extruded) & 300 & $163 \pm 5$ & $185 \pm 2$ & $182 \pm 4$ \\
\hline
\end{tabular}

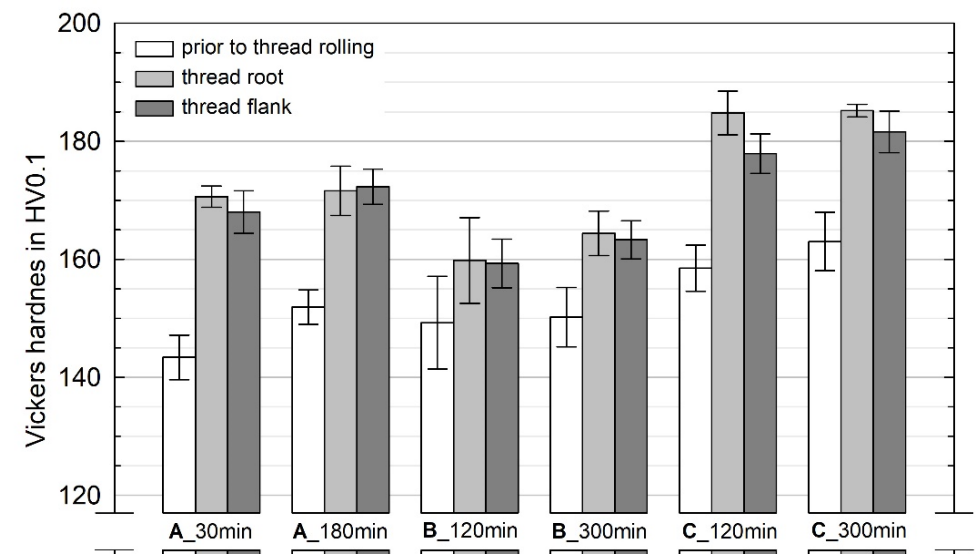

a)
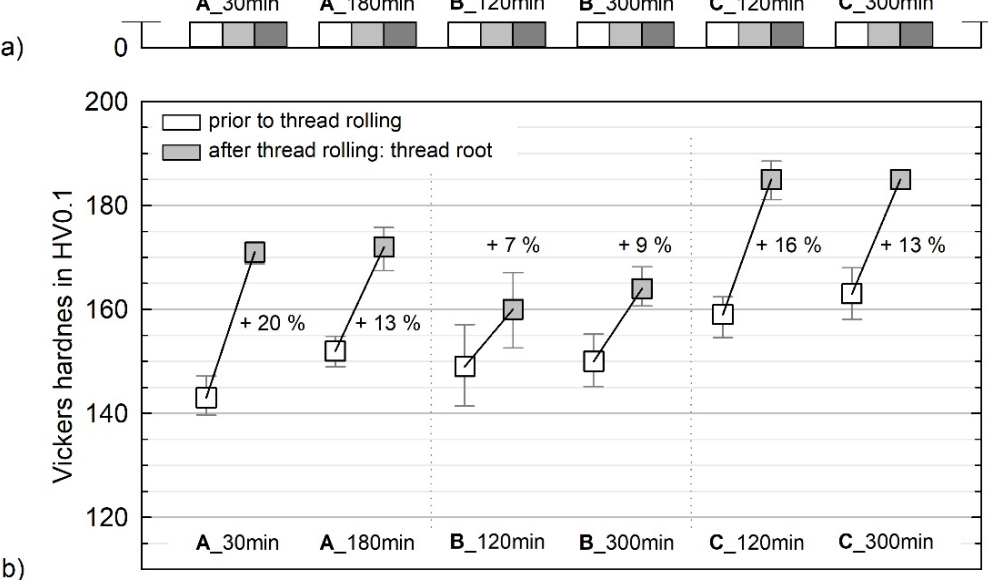

Figure 5. Vickers Hardness achieved for the three different processing routes dependent on the artificial aging time prior to and after thread rolling: (a) comparison between thread root and thread flank for each condition and (b) percentage increase in hardness by thread rolling. The highest hardness and percentage increase after thread rolling is achieved by processing route $C$. 
The distribution of Martens hardness over the longitudinal section of the threaded parts after thread rolling processed by the three different routes and artificial aging times chosen is shown in Figure 6. Each colored square stands for one indent and the local hardness. When the hardness is under $950 \mathrm{HM}$, the square is marked white, whereas a purple colored square displays a hardness over $1850 \mathrm{HM}$. Due to the spacing between single indents of $0.09 \mathrm{~mm}$, in this graphically representation, the thread teeth seem somewhat deformed missing a pronounced thread tip. However, to ensure the hardness measured is not influenced by indents being to close together, the grid of measuring points for scanning was not scaled down.

a)
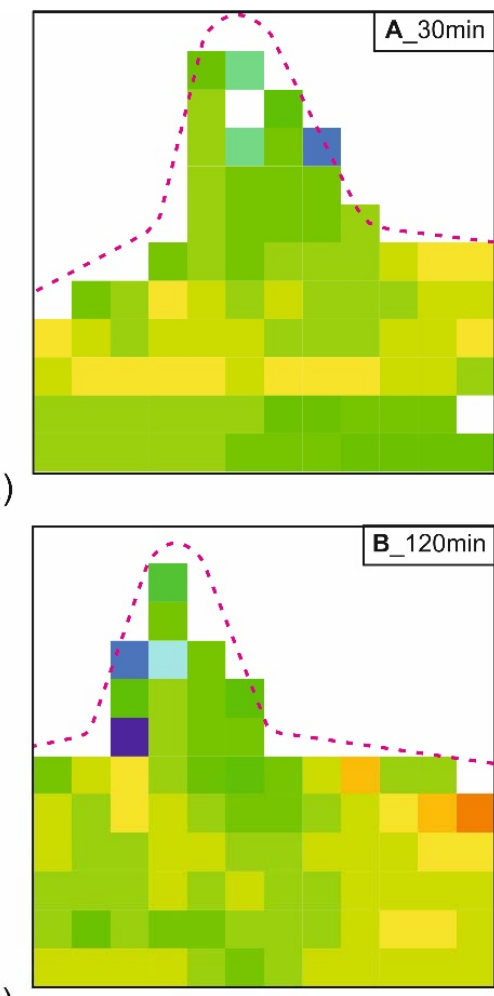

b)

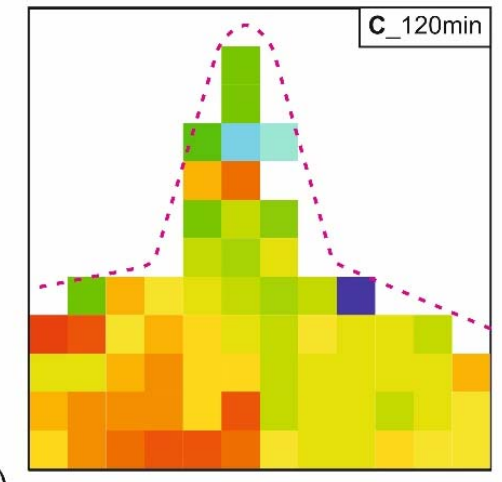

c)

d)
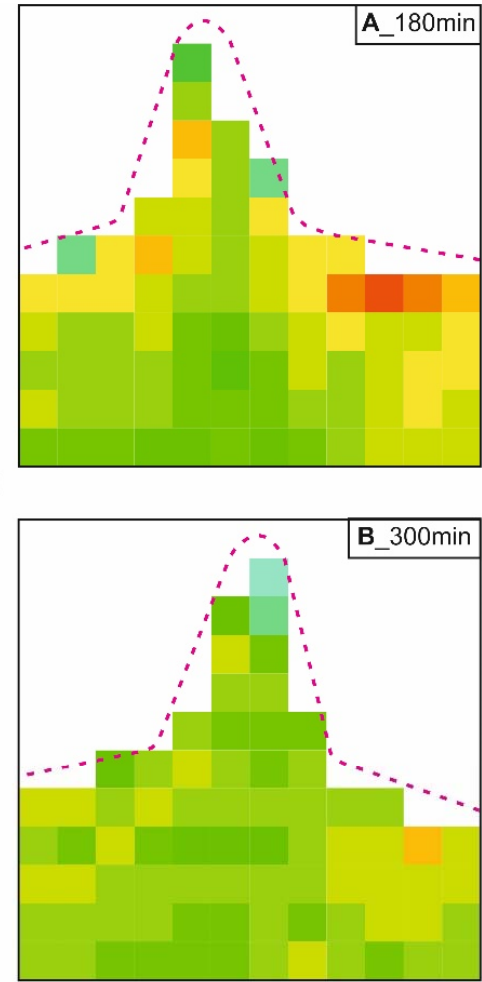

e)

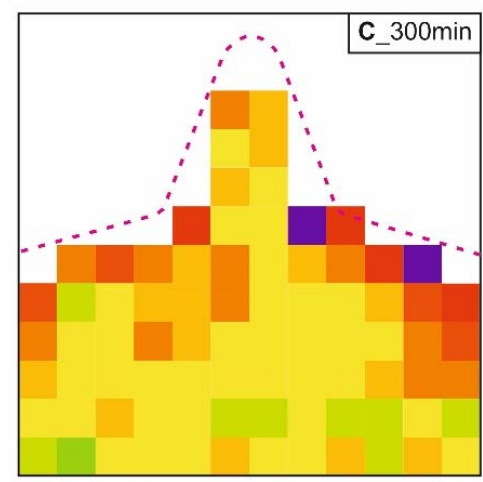

Martenshardness in $\mathrm{MPa}$

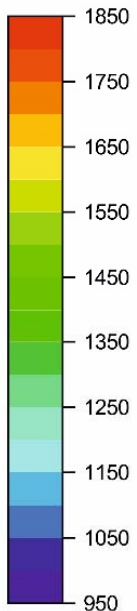

Figure 6. Distribution of Martens hardness over the metallographically polished longitudinal section of the differently processed threaded parts after thread rolling. Schematic contours of thread teeth marked with dashed line in pink. Processing route and initial heat treatment: $(\mathbf{a}, \mathbf{b})$ processing route A (initially solution-annealed), (c,d) processing route B (initially naturally aged), (e,f) processing route $C$ (initially pre-aged). Artificial aging time: $(\mathbf{a}-\mathbf{c})$ local hardness maximum and $(\mathbf{d}-\mathbf{f})$ global peak-hardness achieved. In general, the hardness of the thread root is significantly higher than of the thread flank. The highest overall hardness is achieved by processing route $C$ (pre-aging as initial heat treatment). 
The white, upper figure areas with low hardness are acrylic resin used for mounting the specimens. Further, the white area near the tip of the tooth and near the inner region of the stud processed after route A and aged for 30 min are mostly preparation or measurement artifacts (see Figure 5a). In accordance with the results of the Vickers hardness measurements shown in Figure 4, the threaded parts processed by route B (initial natural aging) exhibits the lowest hardness, when compared to the other routes. The highest hardness is achieved for the pre-aged conditions processed by route $C$. The scans clearly show the hardness distribution across the wire section. In general, the thread root exhibits the highest hardness regardless of the processing route.

\subsection{Surface of the Thread Rolled Parts}

The stereo micrographs of the different processed and thread rolled parts are shown in Figures 6 and 7. It is obvious, that for all threaded parts, independent of the processing route, the threads are not completely formed after the thread rolling process. The closing fold, which is a result from the material pile up during thread rolling to form the teeth, is clearly visible and forms a circumferential crack near the top of the teeth (see Figure 7). In general, the surface of the rolled threads is considerably rough and at the thread root distinct scaling of the material has occurred, which is shown in the micrographs with higher magnification in Figure 8. For the thread rolled studs processed by route $C$ (initial preaging), this effect is significantly less pronounced, when compared to the other processing routes. For route $\mathrm{A}$ and $\mathrm{B}$, the scaled material appears almost like flakes lying on top of the surface. Material abrasion on the surface of the thread root, like pittings or voids, is not noticeable. Comparing the two artificial aging times for the respective processing routes, for the surface appearance, no distinct differences can be seen.

To investigate the rolled threads in more detail, the longitudinal section was analyzed by optical microscopy. As there was no distinct difference between the processing routes noticeable regarding the appearance of the closing fold, Figure 9 shows exemplarily a threaded part processed by route A and artificially aged for $180 \mathrm{~min}$. The closing fold appears as a crack ranging through almost the half of the tooth. At the tip of the tooth, where the fold ends, the opening is delta-shaped. In this micrograph, the scaling at the thread root is also clearly noticeable. 

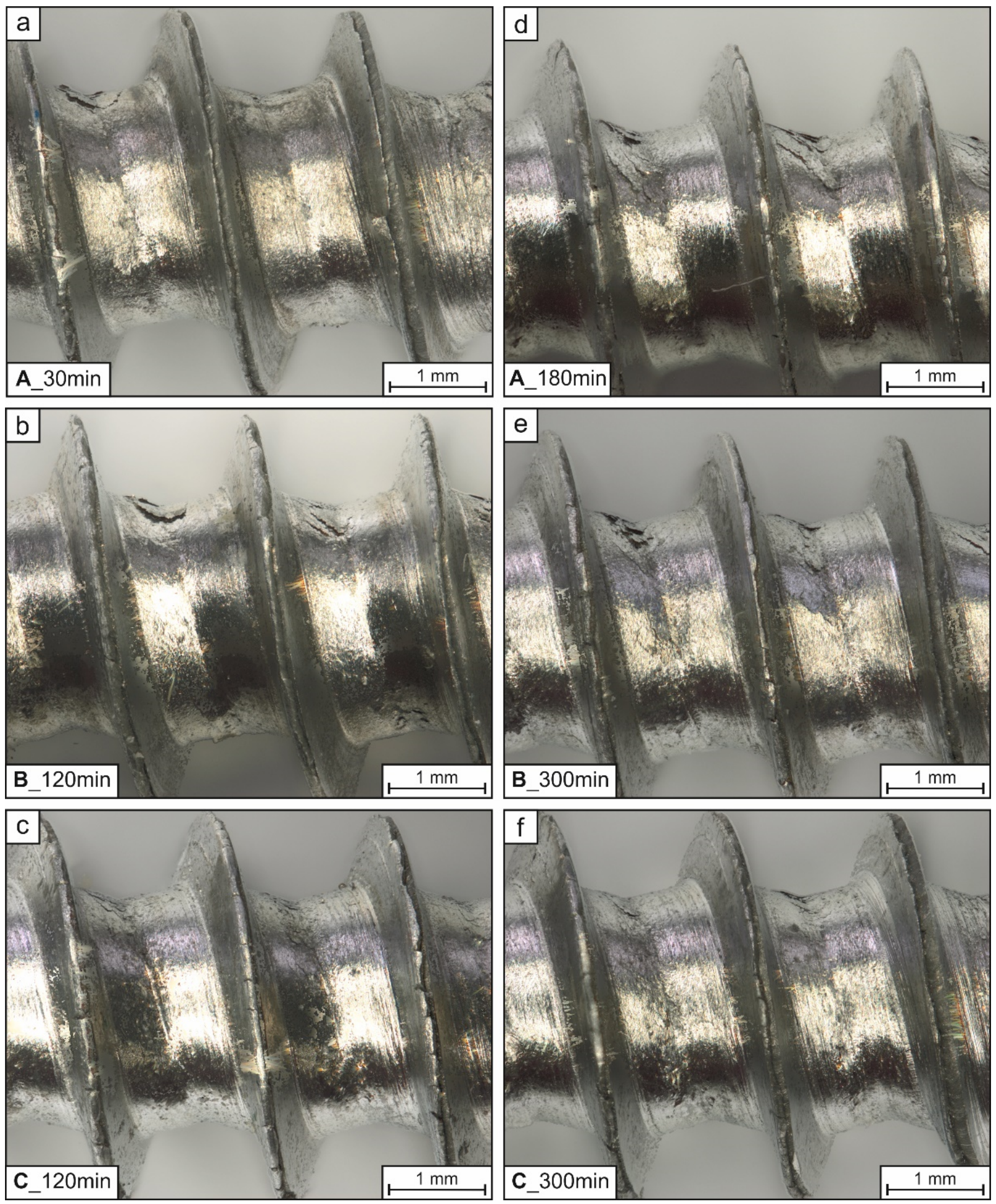

Figure 7. Stereo micrographs of the different processed and thread rolled parts. Processing route and initial heat treatment: $(\mathbf{a}, \mathbf{b})$ processing route A (initially solution-annealed), $(\mathbf{c}, \mathbf{d})$ processing route B (initially naturally aged), (e,f) processing route $C$ (initially pre-aged). Artificial aging time: $(\mathbf{a}-\mathbf{c})$ local hardness maximum and (d-f) global peak-hardness achieved. Independent of the processing route, for all threaded parts, the threads are not fully formed and the closing fold near the top of the teeth is still open. 

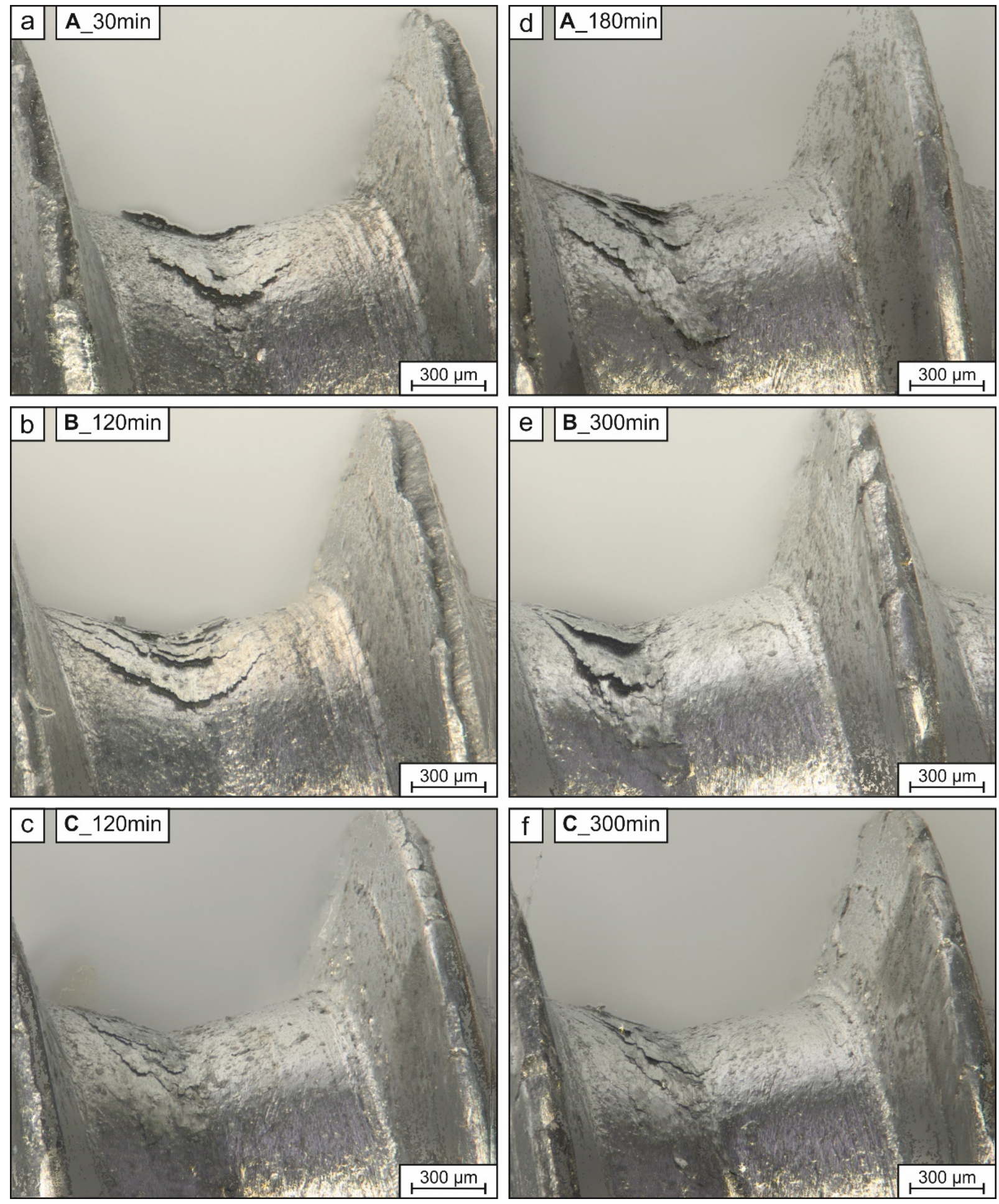

Figure 8. Stereo micrographs of the different processed and thread rolled parts. Processing route and initial heat treatment: $(\mathbf{a}, \mathbf{b})$ processing route A (initially solution-annealed), (c,d) processing route B (initially naturally aged), (e,f) processing route $C$ (initially pre-aged). Artificial aging time: $(\mathbf{a}-\mathbf{c})$ local hardness maximum and $(\mathbf{d}-\mathbf{f})$ global peak-hardness achieved. All thread rolled studs show scaling at the thread root, but this effect is significantly less pronounced for the studs processed by route $\mathrm{C}$, when compared to the other processing routes. 

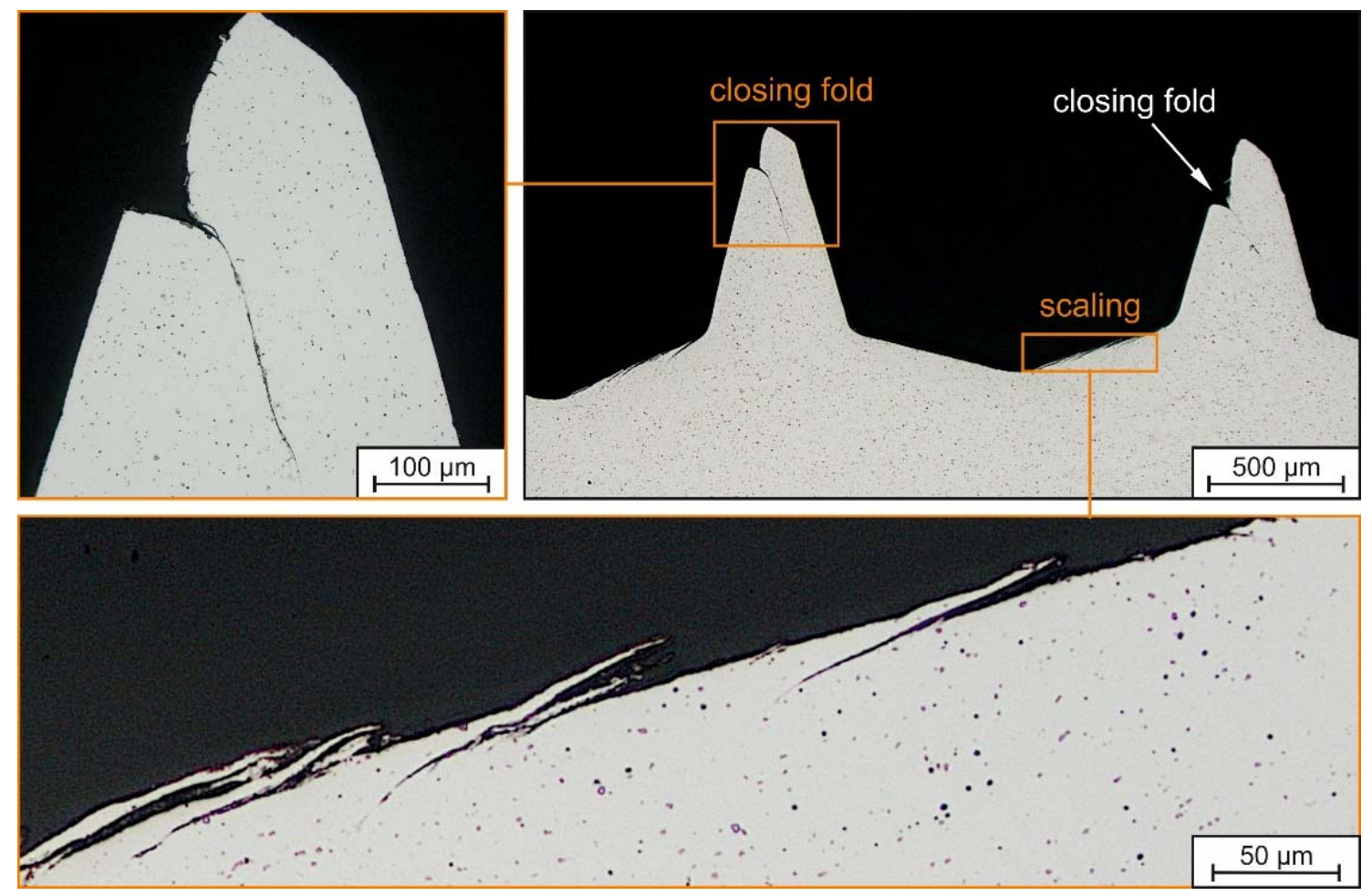

Figure 9. Optical micrograph of a longitudinal section of a threaded part processed by route A. The thread teeth are not fully formed and as a result, the closing fold at the tip of the tooth is clearly visible and has a crack-like appearance. Further, the thread root exhibits distinct scaling.

\section{Discussion}

\subsection{Simulation}

The first step of FE simulation - to obtain input parameters for the rolling simulationwas to determine the properties of the wire stud after extrusion. Due to the pressure localization at the surface area, a strain gradient between the surface and the core of the stud was created showing a typical maximum strain of approximately 2 at the rim while the core area is almost not affected. Similar effects were described in [14], where a reduction of $11 \%$ was evaluated be FE methods. High residual stresses in the surface area are a direct result of this kind of processing.

By further FE simulation, it was possible to calculate the strain distribution and geometry formation due to thread rolling. As was already observed in [13], a very high strain is introduced in this kind of processes because of very high local pressures. These effects have also been confirmed in a study on metric screws in [15]. A local plastic strain of about 10 has been observed in that study using an initial mesh size of $0.1 \mathrm{~mm}$. Due to their geometry, thread rolling of metric screws requires less deformation compared to the screw geometry used in this study, which is suitable for thread forming into plastics. Hsia et al. [15] observed lower plastics strains if the mesh has been chosen to be too coarse. The material forming the thread flanks is moved from the rim of the wire stud to its intended position. As each thread flank is built from two sides, a closing fold is generated which can be easily seen in the micrographs. This fold can be closed using an extended calibration rolling which had not been applied here. The simulation well describes the different phases of thread generation that coincide with experimental observations. The highest amount of deformation is taking place in the thread root area. To avoid scales in this area, a good formability of the material is needed. 


\subsection{Evolution of Hardness Dependent on Processing Route}

The hardness achievable by artificial aging of the extruded aluminum wire studs is significantly influenced by the initial heat treatment. In accordance to the literature $[9,10]$, pre-aging (route $\mathrm{C}$ ) has a positive effect. When compared to the other two processing routes, the highest hardness is achieved by pre-aging, as the metastable Guinier-Preston (GP) Zones formed during pre-aging enable an easier transformation to the strengthening phase $\beta^{\prime \prime}$ by artificial aging [16-19]. In contrast, naturally aging of the alloy, which was conducted in processing route $\mathrm{B}$, leads to the formation of stable $\mathrm{Mg}$-Si co-clusters, which impede the formation of the strengthening phase and as a result, the hardening response during artificial aging is significantly lowered [7-9].

The distribution of hardness over the cross section of the artificially aged wire studs is mostly a result of the strain distribution introduced by extrusion. The experimental data shown in Figure 4 correspond well with the simulation results shown in Figure 1a. The areas of highest strain, which are close to the surface, exhibit the highest hardness. Towards the wire core, hardness decreases due to the lesser amount of strain hardening and lower dislocation density. These findings are in good accordance with [20]. However, the processing route plays a dominant role for the overall hardness achievable and route $\mathrm{C}$, employing initial pre-aging, is seen as most beneficial for achieving high hardness.

For the threaded parts, as indicated by simulations, a correlation between the strain and the local hardness is also expected due to strain hardening at least for lower degrees of deformation. Due to the high degree of deformation, a constant high hardness is achieved at the thread flank and the thread root after the rolling process, while the hardness in the center of the threaded parts is less, as it is demonstrated in Figures 5 and 6. Further, the previous processing route significantly influences the hardness achievable after thread rolling. The pre-aged condition has not only the highest initial hardness, but furthermore, also exhibits a strong hardness increase due to rolling process, as is shown in Figure 5b. This indicates that a sufficient reserve for strain hardening is still present in the stage prior to thread rolling, which allows for the best forming properties in the rolling process despite the highest initial hardness of the pre-aged condition (route C). The thread geometry was well reproduced and the amount of scale in the most critical areas was lowest of the three variants (see Figure 8). Therefore, it seems that pre-ageing has a positive effect on the formability as well.

The overall hardness achieved in the threaded parts is mainly influenced by the thermomechanical route used prior to thread rolling, where route $\mathrm{C}$ seems to be most beneficial. Therefore, pre-aging is an effective strategy to inhibit natural aging and to enhance the hardening response during artificial aging. Furthermore, using this initial heat treatment, a high hardness is achieved after artificial aging while a good formability due to a sufficient strain hardening capacity is still maintained, which is an important requirement for further processing. Summarized, a processing route using initial pre-aging enables excellent mechanical properties and seems to be a promising strategy to be integrated into the industrial multistage forming process for manufacturing aluminum screws. However, for a successful implementation of this complex thermomechanical processing, the underlying mechanisms must be understood, so further research is necessary especially with focus on the relationship between heat treatment parameters, formability and strength.

\section{Conclusions}

In this study, the influence of the thermomechanical processing route on hardness and formability was investigated for a 6056 aluminum alloy. The focus was on an initial pre-aging treatment combined with artificial aging following conventional extrusion prior to final thread rolling. Conclusions can be drawn as follows:

- Using a conventional 6056 aluminum alloy, it is possible to achieve an exceptional high hardness in a thread-formed product using a thermo-mechanical route containing a pre-aging treatment. The maximum hardness, which is obtained after thread rolling, depends on the initial combination of heat treatment and extrusion. 
- $\quad$ Pre-ageing seems to be an appropriate process to achieve a high hardness after extrusion, which cannot be obtained by natural ageing. Followed by artificial ageing of the extruded parts, the differences of pre-aged and naturally aged parts become even more pronounced.

- The hardness increase by thread rolling of a pre-aged condition is higher, when compared to a naturally aged condition. Furthermore, threaded parts made of pre-aged conditions exhibit much less scale at the thread roots where the highest deformation is observed due to a better formability.

Author Contributions: Conceptualization, L.W. and R.J.H.; methodology, L.W. and R.J.H.; validation, L.W. and R.J.H.; formal analysis, L.W. and R.J.H.; investigation, L.W. and R.J.H.; resources, R.J.H. and T.L.; writing—original draft preparation, L.W.; writing—review and editing, R.J.H., K.H., and T.L.; visualization, L.W.; supervision, T.L.; project administration, K.H., R.J.H., and T.L.; funding acquisition, K.H., R.J.H., and T.L. All authors have read and agreed to the published version of the manuscript.

Funding: This work was supported by the German Research Foundation (Deutsche Forschungsgemeinschaft (DFG)) within the Collaborative Research Center SFB 692 “High-strength aluminum-based lightweight materials for safety components" (project number SFB692T7). The publication of this article was funded by the Chemnitz University of Technology in the funding program for open access publishing.

Data Availability Statement: The authors confirm that the data to support the findings of this study are available within the article.

Conflicts of Interest: The authors declare no conflict of interest.

\section{References}

1. Arz, U.; Weber, J.O.; Marx, T.; Berger, C. Mechanical behaviour of aluminum screws Part 1-Static load capacity. Mater. Werkst. 2010, 41, 213-217. [CrossRef]

2. Reinhold, B.; Klose, S.G.; Kopp, J. Schutzsysteme für Verschraubungselemente in Kontakt mit Leichtmetall. Mater. Werkst. 1998, 29, 1-8. [CrossRef]

3. Sieber, M.; Scharf, I.; Härtel, M.; Hellmig, R.J.; Lampke, T. Influence of anodic oxide coatings on screwing behaviour and susceptibility to stress corrosion cracking of self-tapping aluminium screws. Mater. Werkst. 2012, 43, 661-667. [CrossRef]

4. Gröber, D.; Georgi, W.; Sieber, M.; Scharf, I.; Hellmig, R.J.; Leidich, E.; Lampke, T.; Mayr, P. The effect of anodising on the fatigue performance of self-tapping aluminium screws. Int. J. Fatigue 2015, 75, 108-114. [CrossRef]

5. Brendler, G.; Scharf, I.; Härtel, M.; Nickel, D.; Hellmig, R.J.; Alisch, G.; Lampke, T. Vergleich des Anodisierens von Aluminiumschrauben mittels Direkt- bzw. Flüssigkontaktierung. Mater. Werkst. 2011, 42, 672-679. [CrossRef]

6. Rao, A.C.U.; Vasu, V.; Govindaraju, M.; Srinadh, K.V.S. Stress corrosion cracking behaviour of 7xxx aluminum alloys: A literature review. Trans. Nonferrous Met. Soc. China 2016, 26, 1447-1471. [CrossRef]

7. Marioara, C.D.; Andersen, S.J.; Jansen, J.; Zandbergen, H.W. The influence of temperature and storage time at RT on nucleation of the $\beta^{\prime \prime}$ phase in a $6082 \mathrm{Al}-\mathrm{Mg}-\mathrm{Si}$ alloy. Acta Mater. 2003, 51, 789-796. [CrossRef]

8. Saga, M.; Sasaki, Y.; Kikuchi, M.; Yan, Z.; Matsuo, M. Effect of Pre-Aging Temperature on the Behavior in the Early Stage of Aging at High Temperature for Al-Mg-Si Alloy. Mater. Sci. Forum 1996, 217-222, 821-826. [CrossRef]

9. Takaki, Y.; Aruga, Y.; Kozuka, M.; Sato, T. Effects of pre-aging and natural aging on bake hardening behavior in Al-Mg-Si alloys. Mater. Sci. Forum 2014, 794-796, 1026-1031. [CrossRef]

10. Zi, Y.; Zeqin, L.; Leyvraz, D.; Banhart, J. Effect of pre-ageing on natural secondary ageing and paint bake hardening in Al-Mg-Si alloys. Materialia 2019, 7, 100413. [CrossRef]

11. Yang, Z.; Liang, Z.; Leyvraz, D.; Banhart, J. Hardness data related to pre-ageing, natural secondary ageing, and paint bake hardening in Al-Mg-Si alloys. Data Brief 2019, 27, 104494. [CrossRef] [PubMed]

12. Winter, L.; Hockauf, K.; Scholze, M.; Hellmig, R.J.; Lampke, T. Influence of Pre-Aging on the Artificial Aging Behavior of a 6056 Aluminum Alloy after Conventional Extrusion. Metal 2021, 11, 385. [CrossRef]

13. Wick, D. Simulation sowie experimentelle Untersuchung von Materialschädigungen bei Umformprozessen. Ph.D. Thesis, Universität Siegen, Siegen, Germany, 2019.

14. Zottis, J.; Theis Soares Diehl, C.A.; Rocha, A.D.S. Evaluation of experimentally observed asymmetric distributions of hardness, strain and residual stress in cold drawn bars by FEM-simulation. J. Mater. Res. Technol. 2018, 7, 469-478. [CrossRef]

15. Hsia, S.-Y.; Pan, S.-K.; Chou, Y.-T. Computer Simulation for Flat-die Thread Rolling of Screw. In Proceedings of the International Conference on Innovation, Communication and Engineering, Xiangtan, China, 21 January 2016; pp. 1-5. 
16. Yamada, K.; Sato, T.; Kamio, A. Effects of quenching conditions on two-step aging behavior of Al-Mg-Si alloys. Mater. Sci. Forum 2000, 331, 669-674. [CrossRef]

17. Suzuki, H.; Kanno, M.; Itoh, G. A consideration of the two-step aging process in an Al-Mg-Si alloy. Aluminium 1981, 57, 628-629.

18. Dutta, I.; Allen, S.M. A calorimetric study of precipitation in commercial aluminium alloy 6061. J. Mater. Sci. Lett. 1991, 10, 323-326. [CrossRef]

19. Murayama, M.; Hono, K. Pre-precipitate clusters and precipitation processes in Al-Mg-Si alloys. Acta Mater. 1999, 47, 1537-1548. [CrossRef]

20. Berndt, N.; Frint, P.; Wagner, M.F.-X. Influence of Extrusion Temperature on the Aging Behavior and Mechanical Properties of an AA6060 Aluminum Alloy. Metal 2018, 8, 51. [CrossRef] 